\title{
As crianças, o quintal e o mundo: diálogos de Paulo Freire sobre a infância
}

\author{
Elenice de Brito Teixeira Silva ${ }^{1}$ \\ https://orcid.org/0000-0001-8867-9481 \\ Adelson Ferreira da Silva ${ }^{2}$ \\ https://orcid.org/0000-0003-0217-3805
}

\begin{abstract}
Resumo
O presente artigo analisa alguns diálogos de Paulo Freire sobre ser criança, tendo em vista a infância enquanto categoria ontológica, expressa na sua concepção de ser no mundo. Destaca alguns princípios para o campo de estudos da Educação infantil, notadamente, aqueles com ênfase na questão da alteridade, da curiosidade e do cuidado. Problematiza possíveis implicações epistemológicas da sua concepção de ser no mundo, como pressuposto para a constituição da intersubjetividade nas Pedagogias da infância. Tem como objetivo, portanto, examinar algumas reflexões de Paulo Feire sobre sua própria infância, como perspectiva para pensar a inserção social e os processos de constituição da consciência de nossa humanidade, supondo que, a singularidade presente na sua narrativa autobiográfica, inspira a valorização de outras singularidades presentes na infância de cada criança que, com seus quintais e, também, com seus não quintais, são seres no mundo em processos de transformação.
\end{abstract}

Palavras-chave: Paulo Freire. Infância. Educação Infantil.

\begin{abstract}
This article analyzes some dialogues by Paulo Freire about being a child, considering childhood as an ontological category expressed in his conception of being in the world. It highlights some principles for the field of Early Childhood Education studies, notably those with an emphasis on the issues of otherness, curiosity and care. It questions possible epistemological implications of the concept of being in the world, in Freire's dialogues, as a premise for the constitution of intersubjectivity in Childhood Pedagogies. It aims to examine Freire's reflections about his own childhood as a perspective to consider social insertion and the processes of constituting the consciousness of our humanity, assuming that the singularity present in Freire's autobiographical narrative inspires the appreciation of other singularities present in the childhood of each child who, with their backyards and also their non-backyards, are beings in the world in a transformation process.
\end{abstract}

Keywords: Paulo Freire. Childhood. Early Childhood Education.

\footnotetext{
${ }^{1}$ Doutora em Educação pela Universidade Federal de Minas Gerais. Professora Assistente na Universidade do Estado da Bahia - elenteixeira@yahoo.com.br

${ }^{2}$ Mestre em Filosofia e Doutorando em Educação pela Universidade Federal de Minas Gerais. Professor Assistente na Universidade do Estado da Bahia - ferreira.adelson@yahoo.com.br
} 


\section{Partir da infância, começar com as crianças}

Os diálogos de Paulo Freire sobre sua infância e sobre a infância como categoria ontológica expressam sua concepção de ser no mundo como ser da transformação. Esses diálogos encerram alguns princípios para o campo de estudos da infância e da Educação infantil. Entre tais princípios, destacam-se o encaminhamento da alteridade, da curiosidade e do cuidado. Nesse sentido, tanto a intersubjetividade contida na ética da alteridade pela consideração da presença do outro, bem como o exercício da curiosidade como um direito, resulta em implicações epistemológicas para uma Pedagogia da infância fundada na centralidade ontológica do cuidado. Como ética necessária para o exercício da docência na Educação infantil, o cuidado na perspectiva freiriana, compõe-se do que é próprio, particular e diferente no outro; associado, portanto, à vontade de saber e conhecer algo novo.

Questiona-se, entretanto: quais implicações epistemológicas são possíveis derivar da concepção de ser no mundo como ser da transformação, aludida nos diálogos de Paulo Freire, para a constituição da intersubjetividade humana nas Pedagogias da infância? Procura-se, a partir dessa questão, analisar algumas narrativas de Paulo Freire sobre sua própria infância, como condição da experiência histórica de inserção social no mundo e de constituição da consciência de nossa humanidade. Nesse sentido, a singularidade presente na narrativa autobiográfica de Paulo Freire, inspira a valorização de outras singularidades presentes na infância de cada criança que, com seus quintais e não quintais, estão no mundo, muitas vezes, mais adaptadas do que inseridas como seres da transformação.

Paulo Freire se apresenta como um "menino nascido no Recife, de uma geração que cresceu em quintais, em íntima relação com árvores". E completa: "minha memória não poderia deixar de estar repleta de experiências de sombras" (FREIRE, 2012, p. 25). A sombra das árvores intercepta a luz do sol, mas não produz escuridão. Antes, porém, produz formas, contornos, assombros imaginados, figuras animadas pelo poder da criação infantil. Essas formas e contornos não são a geometria dos geômetras; mas sim, a geometria da percepção das crianças, não linear e perspectivamente desfigurada. Por isso, o quintal que, para Paulo Freire, era a sua imediata objetividade, é também o primeiro mundo sublinhando como algo importante em sua vida.

\footnotetext{
A terra que a gente ama, de que a gente sente falta e a que se refere, tem sempre um quintal, uma rua, uma esquina, um cheiro de chão, um frio que corta, um calor que sufoca, um valor por que se luta, uma carência sentida, uma sobra que maltrata a carência, uma língua que se fala em diferentes entonações. A terra por que se dorme mal, às vezes, terra distante, por causa da qual a gente se aflige tem que ver com o quintal da gente, tem que ver com esquinas de ruas, com os sonhos da gente (FREIRE, 2012, p. 41).
}

Ora, ainda que a infầncia elaborada nos princípios da pura racionalidade não compartilhe uma percepção assim de quintais, ruas e esquinas, não se pode, todavia, dizer que todas as crianças estão isentas de tal sensibilidade. Muitas crianças são exiladas de seus próprios quintais para que outras possam tê-los em demasia. No fundo, Paulo Freire mostra que a terra que a gente ama é aquela conectada com nossas emoções e memórias. Muitas crianças foram desconectas de seus quintais e, por isso mesmo, seus sentimentos foram lançados no exílio. Para essas crianças, a melhor educação é aquela que, de alguma forma, poderá restituir essa carência.

Muito já se disse que Paulo Freire não posicionou as crianças como sujeitos centrais de suas pedagogias e seus escritos (KOHAN, 2019), embora outras possibilidades tenham sido criadas para se pensar uma educação das crianças das classes populares como espaço/tempo dialógicos na gênese de sua pedagogia como prática da liberdade (ÂNGELO, 2006). Por outro 
lado, a área de Educação Infantil, apesar de afirmar a contribuição das instituições de Educação Infantil para a justiça social, a igualdade de oportunidades para todas as crianças e a garantia dos direitos de aprendizagem e desenvolvimento (BARBOSA, 2018), tende a estabelecer um diálogo muito frágil na tarefa de recuperar as bases de uma pedagogia progressista e humanista no Brasil.

Mais do que nunca, esse exercício tenso de recuperação dos fundamentos humanistas e progressistas das pedagogias é um enfrentamento na afirmação do ideal de Educação Infantil como direito, como espaço privilegiado de produção simbólica e cultural contra as condições extremas das infâncias e a invisibilização dos bebês e crianças. Um enfrentamento necessário para o fortalecimento da área de conhecimento da pedagogia da infância que, efetivamente, se ocupe da constituição das infâncias concretas, plurais e diversas pelas crianças nas relações que estabelecem com a realidade social (ROCHA et al. 2016). Ou seja, trata-se de um enfrentamento no campo teórico, dos fundamentos da formação em Pedagogia, das políticas e das práticas educativas, que possa resistir ao contexto de padronização via modelo de competências. Um modelo que sacrifica os tempos da infância em nome de uma suposta eficiência na aplicação de recursos na escolarização dos mais pobres.

Esse contexto abrange países sul americanos, incluindo o Brasil, em um movimento de inserção da Educação Infantil nas políticas nacionais de currículo que têm como pilar o desenvolvimento integral de bebês e crianças, mas são pressionadas pela antecipação do ensino de conteúdos de aprendizagem, conforme análise comparada da legislação da área (UNESCO/BRASIL, 2013). A crença na intervenção precoce como saída para a quebra de círculos de pobreza, que identificamos nos relatórios de organismos financeiros internacionais (NAUDEAU, 2011; NAVARRO, 2014), coloca em jogo essas disputas pela formalização do que se aprende e do que se ensina a bebês e crianças. As disputas e pressões apelam ao instrumentalismo das práticas e expurgam possibilidades de atividades narrativas e estéticas fundadas nos círculos concretos das culturas.

É nesse limiar pela curricularização das experiências das crianças (BRASIL, 2017) e de investidas na instrumentalidade das práticas que a política de infância e de Educação Infantil no Brasil se situa. Essa curricularização é observada, a título de exemplo, na publicação recente de editais de obras didáticas, obras literárias com temas pré-definidos e obras pedagógicas de "preparação para alfabetização baseada em evidências" (Edital PNLD/MEC 2022 de 28/09/2020). Além disso, atravessamos a ampliação das desigualdades de acesso aos bens culturais pelas crianças no centro da crise sanitária, política, econômica e social provocada pela pandemia de COVID-19, além de uma mudança na agenda ideológica de governo. Enfim, o cenário atual pressiona a Educação Infantil pela defesa de uma identidade própria baseada na ontologia dos bebês e crianças, contrapondo-se a interesses e práticas de avaliação do progresso de desenvolvimento, modularização das experiências e emergência da modalidade não presencial.

Partir da infância, no sentido de fazer um recuo ontológico, pode ser um caminho na tarefa de explicitar os fundamentos da educação e das Pedagogias da infância que nos movem em um cenário de incertezas para o futuro das crianças e de todos nós. O exercício que Paulo Freire faz, de voltar à infância à sombra de uma mangueira, por meio das memórias dos quintais da antiga casa em Recife, é um exemplo desse recuo à condição do ser que chega ao mundo e que, pela ação social e atividade, tornará esse mundo um universo simbólico e significativo para si. É esse exercício de voltar à infância narrada por Paulo Freire nos seus diálogos que move a construção deste artigo, no sentido de restituir as bases humanistas de sua Pedagogia que podem fundamentar políticas e práticas de cuidado e educação das crianças. 


\section{Diálogos de Paulo Freire sobre a infância: fundamentos ontológicos e ético-políticos de uma Pedagogia progressista}

As experiências que constituem as memórias de infância contadas no livro à Sombra desta Mangueira e nas Cartas à Cristina, assim como outras vivenciadas durante o exílio e narradas à sua prima Nathercinha - com nove anos de idade à época das correspondências (1967-1970) -, testemunham alguns encontros de Paulo Freire com a sua infância e com a infância como condição da humanidade que não nasce pronta; uma infância como chegada e nascimento (ARENDT, 2009), que atualiza o mundo como lugar do novo cotidianamente. Nesse sentido, a infância significa o vivido aqui e agora, uma memória que se projeta para dentro e para fora de si mesmo, com atos permanentes de criação e recriação do real, do universo simbólico, da imaginação, da fantasia e da transformação do ser social que se insere no mundo.

A relação entre infância, memória e experiência na narrativa autobiográfica de Paulo Freire já consistiria por si, pressupostos de uma educação humanista da infância. Nela é possível encontrar um delineamento de princípios que colocam nossa inserção no mundo em outra ordem; aquela que interroga, entre outras coisas, o processo de expansão da oferta de Educação Infantil. Não se trata simplesmente de acumular a máxima quantidade possível de crianças atendidas nas instituições de educação infantil, pois isso é uma política básica. Trata-se, portanto, de cuidar da qualidade dos contextos de experiências oferecidos aos bebês e crianças, de modo que se possa anunciar a perspectiva de um novo humanismo. Assim, o fato de que "somos seres no mundo, com o mundo e com os outros, por isso seres da transformação [...]" (FREIRE, 2012, p. 37), implica considerar a voz ativa da criança para que uma educação humanista oriente a constituição da infância.

Tal ontologia tende a constituir o humano intersubjetivamente, transformando a si mesmo na relação com o outro. Esta relação institui uma alteridade que resulta na fundamentação de uma ética do cuidado. Nesse sentido, o cuidado humaniza e funda o ethos do humano, os valores e atitudes de abertura e envolvimento afetivo com o outro, de cooperação e solidariedade, o que instaura a vida coletiva, conforme defende Boff (2014). Por essa ética do humano e da alteridade se justificariam práticas de cuidado e educação, tendo em vista a preservação da vida, o compartilhamento e produção das culturas e a criação de possibilidades de desenvolvimento humano contra toda forma de determinismo e barbárie.

Assim, podemos dizer que pela ética do cuidado com a vida humana se justificaria também a instituição de espaços e tempos de coexistência, convivência e interações que se voltam para os sentidos da vida e da infância; espaços/tempos que possam fazer frente à radicalização das condições da infância e as desigualdades sociais que assolam a vida das crianças. Defendemos que é pelo cuidado como ética da alteridade (SILVA, 2020) ou como amorosidade, nos termos freirianos (FREIRE, 1996), que firmamos nosso compromisso com o mundo, as pessoas e as coisas. É, pois, pelo cuidado, que é possível construir uma outra ética amorosa (HOOKS, 2020), que defenda o direito de todas as crianças à liberdade, à educação, aos bens culturais, à vida plena e alegre.

A ética do cuidado, da alteridade e amorosidade reivindica a integralidade do humano na educação das crianças contra qualquer prescrição reducionista. O que argumentamos é que há uma ética do cuidado e da amorosidade com o mundo, as crianças e as pessoas em Paulo Freire, que fundamenta o campo ontológico das relações humanas e um projeto de educação progressista.

Essa ontologia do ser no mundo interroga, interpela e circunscreve uma epistemologia para os campos de estudos dos bebês, crianças, infâncias e Pedagogia. Interroga a nomeação da inserção dos bebês e crianças nas escolas como uma adaptação de quem chega a um dado objetivo imutável. Como seres da transformação, a inserção de bebês e crianças em um contexto público como o das instituições de Educação Infantil, transforma um todo significativo - os 
espaços, tempos, materiais e relações - em experiências históricas de todos os envolvidos, incluindo aí, as famílias, sobretudos as mulheres, mães trabalhadoras, e as/os profissionais da Educação Infantil. Trata-se, portanto, de uma ontologia que interpela o imaginário coletivo sobre o mundo que se oferece aos bebês e crianças e a política de infância e de educação em determinado contexto histórico e cultural; e, ainda, circunscreve uma epistemologia como modo de conhecer, pensar e produzir saberes sobre esses seres sociais que produzem suas infâncias singulares em contextos coletivos cada vez mais alargados.

Ao partir da infância que brinca no quintal da casa compreendendo-a como o seu primeiro mundo objetivo imediato e "primeiro não eu geográfico", Freire $(2012$, p. 40) se volta para o processo de constituição do humano, daquilo que lhe constitui um eu singular frente a outros egos, a outras materialidades, a outros modos de pensar, de se comunicar e de agir no mundo. Com essa retomada ao campo originário da constituição humana nas condições concretas de existência, desde a infância, Paulo Freire ratifica a concepção de que somente pelo fato de agirmos no mundo com os outros é que a história de cada pessoa se torna um espaço/tempo de possibilidades. Porém, esse caráter relacional, assim como a capacidade humana de conhecimento, não se faz sem curiosidade. A curiosidade em Paulo Freire alcança o status de um princípio fundante para o conhecimento na medida em que considera que o "conhecimento começa com a curiosidade e se desenvolve com a experiência" (SILVA, 2017, p. 181).

Essa compreensão ontológica é fundamental para o entendimento de que o nascimento de um bebê, sua inserção nos espaços públicos, a constituição das atividades de falar, pensar, agir, imaginar, escrever, desenhar, ler, são formas históricas e culturais de exercício da transformação, do eu, dos outros e dos contextos sociais de desenvolvimento. São exercícios, muitas vezes tensionados e tangenciados pela presença dos adultos, de conhecer e se apropriar do mundo pela curiosidade de apreensão deste mundo. Por estas razões, todo projeto de política de Educação Infantil, sobretudo de crianças das classes populares em contextos de desigualdades, é um projeto político, assim como são as formas de os adultos se colocarem na relação com as crianças.

\section{Descobrir a razão de ser das coisas pela comunhão com as coisas: princípios epistemológicos}

À sombra desta mangueira (2012) parece ser mais que o título de um livro de Paulo Freire. É um livro que, como ele mesmo diz, revela o seu mundo mais particular. Mostra não apenas o suporte que tornou possível a existência, mas também, a sobrevivência, isso é, a condição de permanecer vivo apesar das adversidades do seu tempo histórico. Por isso, ele descreve:

o título deste livro é, assim, uma licença que me permito e com a qual sublinho a importância que tiveram na infância as sombras de diferentes árvores - mangueiras, jaqueiras, cajueiros, pitombeiras. Sombras em que, à luz clara do dia, fui me acostumando a descobrir a razão de ser de ruídos que, no fundo das noites, indecifrados me assustavam. (...) sombra, luminosidade, céu azul, horizonte fundo e amplo dizem de mim. Sem eles, sobrevivo mais do que existo (FREIRE, 2012, p. 26, grifos nossos).

É também à sombra da mangueira, no exercício de pensar as experiências que lhe fizeram um eu pensante da educação popular, que Paulo Freire desdobra ideias sobre o mundo como objeto de conhecimento e transformação. Que mundo é esse, dado a conhecer pelos recém-chegados a ele? Segundo Freire (2012, p. 45) a terra da gente "é sua geografia, sua ecologia, suas terras, seus vales, suas montanhas, suas florestas, seus rios, meus minerais, seus 
animais, seus pássaros, seus campos, suas colinas, seus desertos, mas é o que fazemos dela, nela. Minha terra não é, afinal, uma abstração".

Paulo Freire recupera as experiências com o mundo natural, com as árvores, os cheiros, os sons como memória e as colocam na narrativa. Esta acepção do mundo como o seu espaço, sua cultura e imaginário coletivo posiciona a infância como o tempo de experimentações novas e singulares. Portanto, o mundo que existe para a criança é apropriado na relação dialética criança-mundo através de suas ações e atividades, como a comunicação emocional e sensorial, a exploração, a fala, a escuta, o pensamento, a imaginação, o desenho, a leitura, a escrita e a brincadeira.

O princípio epistemológico freiriano de descobrir as razões de ser das coisas pela comunhão com elas, agrega um conjunto de significações éticas, políticas, estéticas e didáticopedagógicas para educação da primeira infância. Para Freire (2012), o isolamento nega a comunhão e a inteireza com a qual conhecemos; nega o fato político incontestável de que conhecemos com o corpo inteiro, razão-emoção, razão-sentimento, razão-paixão.

O Ser social no mundo é ser da transformação cuja atividade não se limita a mexer no mundo (FREIRE, 2012), um verbo muito pertinente para pensarmos a ação social dos bebês e das crianças. Mexer no mundo e explorar os contextos de sua convivência significa interferir e transformar em lugares de si; significa agir e, por essa atividade, constituir a consciência de si e do mundo. Na compreensão de Freire (2012, p. 33) acerca da relação dialética atividadeconsciência, eu-mundo, consciência-mundo, "toda operação no mundo envolve uma certa compreensão dele". Ficar em pé, balbuciar, pegar um objeto, explorar, engatinhar, tocar, falar, andar, brincar, são modos de conhecer e compreender o mundo. O que essa compreensão pode significar para os estudos dos bebês e das crianças, bem como para as pedagogias da infância?

Em primeiro lugar, uma compreensão assim formulada percebe que as crianças são fazedoras de coisas, produtoras de linguagens e culturas que interferem nos contextos com suas perguntas, intenções e curiosidades. Os estudos dos bebês e da infância, assim como as pedagogias da Educação Infantil que se definem enquanto humanistas e progressistas, não podem oferecer um pacote pronto às crianças. Tal decisão, incorreria, pois, em flagrante negação de sua atividade criadora. Em segundo lugar, cumpre reconhecer que a humanização requer a transformação do mundo em um ambiente para si e para o outro; decisão tal que implica a descoberta das razões de ser das coisas em comunhão com elas. Essa perspectiva pode orientar um currículo da Educação Infantil que considera as experiências das crianças como comunhão com as coisas, ou, como diria Paulo Freire (2012), de um exercício de experimentação que instaura nossa existência no mundo.

A descoberta da razão de ser das coisas, na perspectiva freiriana, é a matriz originária do conhecimento sobre o mundo pelas crianças. Tal descoberta só é possível pela ação no mundo, pela atividade humana de transformar as coisas estando em comunhão com elas. Um projeto de cuidado e educação coletivo que se aventure a dialogar com os fundamentos de uma pedagogia progressista em Paulo Freire (2012), não deve prescindir, pois, da criação de contextos que possam: i) superar as intenções da prática educativa fundada na pura adaptação; ii) viabilizar possibilidades de inserção criativa das crianças; iii) valorizar a imaginação por meio da constância de atos de experimentação; iv) superar a predominância da pura transmissão de conteúdo; v) gerar a necessidade de estar com o outro; vi) valorizar o estranhamento do mundo como ponto de partida; vii) partir do princípio de que as crianças são seres da inteireza que conhecem o mundo, os outros e a si mesmas com o corpo todo; viii) retroalimentar o exercício da curiosidade e da pergunta; ix) compartilhar com as crianças o espanto e a alegria; $\mathrm{x})$ compreender a prática educativa com bebês e crianças como um fenômeno de inserção no mundo em permanente transformação.

Compreendemos que esses princípios, acima elencados, são fundamentais para a construção de contextos sociais de proteção e desenvolvimento capazes de gerar oportunidades 
de vivenciar experiências históricas, ideias e intencionalidades. Todavia, compreendemos também que, na via contrária de ideais freirianos, estão aqueles setores da sociedade para os quais as intenções, desejos, interesses e os quereres das crianças pouco importam para a prática educativa. Procurou-se, nesta seção, com esses princípios extraídos dos diálogos de Paulo Freire sobre a infância, evidenciar a intenção educativa freiriana de compartilhar com as crianças o espanto e alegria, bem como sua compreensão da prática como um dado dando-se (GUIMARÃES; FREIRE, 2011), como algo que acontece cotidianamente com as crianças e seus professores e professoras.

\section{Compartilhar o espanto e a alegria: desvelando as intenções da prática educativa com bebês e crianças}

Se a produção de saberes com as crianças é orientada pela descoberta da razão de ser das coisas em comunhão com estas coisas, como vimos na seção anterior, então, a criação de contextos de descoberta é fundamental nas pedagogias construídas com bebês e crianças. A expressão descoberta da razão, nesse texto, tem o sentido desenvolvido por Paulo Freire (2012) na sua crítica à natureza cientificista do processo de conhecer. O processo cognoscitivo, na acepção freiriana, envolve sentimento, percepção, ação, paixão e "razão também" (Ibid. p. 28); ou seja, a razão de estar com as coisas, em relação com elas, como o próprio autor destaca. Nesse sentido, criar contextos de descobertas implica desvelar a intenção da prática educativa como projeto de justiça social para as classes populares, de trabalhadores e trabalhadoras, cujas condições de vida encontram-se entre a barbárie humana e o aprofundamento das desigualdades.

Paulo Freire (1994), ao compartilhar o espanto e a alegria com uma criança em um contexto de extrema privação das liberdades individuais e dos valores democráticos, tal como na Ditadura civil-militar no Brasil nos anos 1960, explicita intenções de cuidado e educação que são importantes para as Pedagogias da infância. No livro A casa e o mundo lá fora: cartas de Paulo Freire para Nathercinha (2016), Nathercia Lacerda conta sobre suas correspondências com o primo Paulo Freire entre os anos 1967 e 1969, parte do período em que este esteve no exílio. Paulo Freire já havia comentado sobre essas correspondências com uma criança nas suas Cartas à Cristina:

\footnotetext{
Antes de Cristina, no meu primeiro momento de exílio, o do Chile, após dois meses na Bolívia, tive outra correspondente, Nathercinha, prima de Cristina. Compartilhei com ela o espanto e a alegria de criança, em que de novo me tornava, quando vi, pela primeira vez, a neve em Santiago, nas proximidades da cordilheira onde morávamos, mas também quando fui para a rua com meus filhos para "meninizar-me", fazendo bolas de neve e expondo-me inteiro à brancura que caía em flocos sobre a relva, sobre meu corpo tropical (FREIRE, 1994, p. 28).
}

Compartilhar o espanto e alegria com uma criança em tempos sombrios. O que é escolhido para a narrativa chama atenção, assim como a atitude dialógica de corresponder à curiosidade da menina que tentava compreender o sumiço do primo e conhecer o país onde ele passara a morar, como conta Lacerda (2016) no livro. Em todas as cartas enviadas à prima, Paulo Freire se posiciona como um amigo e capricha nas letras para que a criança pudesse ler, conforme observou Madalena Freire em carta à Nathercinha (LACERDA, 2016). A posição de amigo estabelece um diálogo democrático e de alteridade, observado nas perguntas que comunicam o interesse em saber os sentimentos e as experiências da criança, e não apenas, a de responder o que ela perguntava nas cartas. O diálogo democrático de quem se coloca em posição de falar e ouvir, de dar continuidade às intenções das crianças, de atender à curiosidade, 
espantar-se com elas e ampliar seus interesses, são indícios que encontramos na leitura das cartas de uma concepção de criança como interlocutora ativa; como ser social que é afetado pelos acontecimentos, que percebe e pensa sobre o que acontece, mas que, sobretudo, atribui sentidos e transforma o conteúdo das relações e comunicações entre eles.

Nos diálogos com Nathercinha, Paulo Freire se coloca sensivelmente, tomando como referência a linguagem poética para descrever o cotidiano, o lugar, suas cores e a estação do ano. Toda essa estética da sensibilidade que recupera a alegria, o estado de contentamento, com o qual, a criança, quase sempre se comunica, mesmo, muitas vezes, em condições de extrema adversidade. A estética da sensibilidade pode ser observada num trecho da terceira carta, de 1967: "a gente olha pras roseiras e parecem gente rindo. Meninos rindo, com a pureza do riso das crianças" (FREIRE in LACERDA, 2016, p. 57). Esse trecho encerra o pressuposto de que a poética pode apresentar o espaço, tal qual a geografia apresenta um lugar. Porém, o lugar está situado no espaço. E se todo lugar está situado no espaço, então, todo lugar pode ser poético. $\mathrm{O}$ exílio não é o exilado. Por isso, se houver beleza no olhar daquele que percebe, é possível expressar bons sentimentos por meio de uma descrição. Assim, a descrição poética é uma das formas de apresentar o espaço, o lugar e as pessoas. Parece que Paulo Freire quer mostrar que, mesmo em tempos sombrios, infecundos de liberdade e justiça, há que se preservar uma maneira de se comunicar com a criança e com a infância. A condição muitas vezes malfadada do mundo adulto, nesses momentos, deve ser colocada em suspenso.

Com isso, podemos pensar que as cartas de Paulo Freire para Nathercinha simbolizam uma atividade de zelo e desvelo, comunhão e pré (ocupação) com a criança, que não é outra coisa que não cuidado. Cuidado compreendido como ética da alteridade que funda nossas ações em relação aos outros (SILVA, 2017; SILVA e SILVA, 2018), sobretudo quando esse outro encontra-se em posição de dependência e fragilidade, como as crianças. Já dissemos que essa ética é fundamento das políticas de educação das crianças. Compartilhar o espanto, a alegria e meninizar-se são intenções e ações de uma prática educativa que reconhece sua centralidade como política de cuidado na vida das crianças; como política de coexistência entre pares de idade e entre gerações diferentes; como compartilhamento de experiências sociais diversas que gere oportunidades de trocas simbólicas e ampliem os imaginários coletivo e pessoal desde a infância.

O verbo meninizar utilizado por Paulo Freire merece uma atenção especial. Tornar-se menino de novo. O menino que descobre as razões de ser das coisas em comunhão com elas. Que experimenta a neve, sente, percebe e constitui memórias pela atividade de explorar, brincar, comunicar. Enfim, de vivenciar a neve expondo-se a ela com o corpo inteiro. Corpo que toca, sente, percebe, imagina, narra e significa a neve para os outros e para si. O trecho da primeira carta enviada à Nathercinha no outono de 1967 dá conta de mostrar a condição de tornar-se menino pela ação de brincar para vivenciar e descobrir a neve em Santiago; de tornarse menino por sentir-se menino.

\footnotetext{
A neve caía em cima de mim, no meu chapéu, no meu abrigo. A neve caindo parecia poeira do céu. E eu me senti menino de novo e quase brinquei de fazer bonecos de neve. É uma coisa boa, Nathercinha, que a gente nunca deixe de ser menino. Os homens atrapalham as coisas, complicam tudo. (...) Cresça, mas nunca deixe morrer em você a Nathercinha de hoje, que começa a descobrir o mundo, cheia de curiosidades (FREIRE in LACERDA, 2016, p. 50/51, grifos nossos).
}

Tornar-se menino de novo é uma figura de linguagem para expressar a condição de quem deseja experimentar as coisas para se apropriar delas; de compartilhar com as crianças o espanto de quem chega ao mundo e alegra-se a cada pequena descoberta. Sem colocar o compartilhamento desse espanto com as crianças não nos parece possível construir uma 
pedagogia com elas. Uma Pedagogia que, ao compartilhar cuidados, compartilha curiosidades sobre o mundo e as alegrias das descobertas, que no fundo, significam a mesma coisa.

Em contextos de guerra, de condições extremas de violência e pobreza, de privação de direitos civis e políticos, de pandemias e necropolítica, a metáfora de voltar a ser criança foi muitas vezes recuperada por pedagogos, poetas e trabalhadores da causa comum. Janusz Korskak (1981), por exemplo, judeu, professor e educador polonês que viveu o extermínio nazista durante a segunda guerra mundial em Varsóvia, não abandonou as crianças de seu orfanato sob promessa de ter a vida poupada. Morreu por elas após ter escrito "Quando eu voltar a ser criança", uma ficção em que se propôs a pensar no que faria se voltasse a ser criança e a vivenciar os problemas e as alegrias desse tempo da vida. Binjamin Wilkomirski (1998), também vivenciou o horror da perseguição nazista e recuperou suas memórias da infância desse período (1939-1948) como forma de investigar a si mesmo; foi além ao oferecer testemunho de que as experiências da infância são fortemente eternizadas nas memórias e nas narrativas; são experiências de intensidade, de afecção e constituição do humano e, por essa razão, quais experiências nossa sociedade possibilita que as crianças vivenciem deve ser uma preocupação social, educacional e política.

A narrativa de Freire é rica em descrição. Uma narrativa que recompõe a memória das experiências. Experiências com a neve, que, assim como as experiências com as sombras embaixo das árvores na sua infância, foram construídas pela exploração, pela brincadeira e pelas vivências das sensações, percepções, cheiros, ruídos, cores, temperaturas. Paulo Freire atesta a importância dessa ação com as coisas, da comunhão, da experimentação ou da atividade de produzir consciência e significados sobre elas. Ele insiste em todas as cartas no valor da brincadeira como expressão do riso, da liberdade de criar e da alegria de viver; como "vontade de fazer as coisas, de transformar o mundo" (FREIRE in LACERDA, 2016, p. 58). Na quinta carta, de janeiro de 1969, ele escreve: "a gente também precisa brincar. Até quando a gente já está grande, como mamãe, papai, como eu que já estou ficando de barba branca, a gente precisa brincar" (FREIRE in LACERDA, 2016, p. 64).

A brincadeira como ação transformadora do mundo e de nós mesmos, como expressão máxima de nossa meninez e nosso espanto com o mundo, é um legado para pensarmos os projetos de educação e cuidado das crianças e de suas infâncias. Reservar o direito à alegria, à vontade e à liberdade frente a uma necropolítica (MBEMBE, 2016), aprofundada nesses tempos de fechamento das escolas de Educação Infantil em decorrência da pandemia de COVID-19. Uma necropolítica que instrumentaliza o Estado para decidir quem deve morrer e quem pode ser relegado aos seus próprios recursos. A educação das crianças, nesse contexto, tem servido como lente para avaliarmos como o estado cuida e se responsabiliza pela proteção de suas crianças ou pela forma como arranca a única forma de criação e renovação do mundo, como diz Hanna Arendt (2016).

A dialética criança-mundo perpassa toda a arquitetura das cartas de Paulo Freire à uma criança, configurando premissa para as pedagogias da infância que atenta para o processo de constituição humana e para o patrimônio da humanidade que desejamos que as crianças se apropriem. A casa azul, o jardim transformado pelas mudanças de estação no Chile ou pela seca que assolava Santiago nos idos dos anos, as transformações na Cordilheira dos Andes e nas árvores do quintal, ou mesmo a chegada do Homem à lua e os discos que Nathercinha ouvia em casa, servem como mediadores culturais das conversas.

Na política nacional de Educação Infantil temos indicações para um currículo concebido como "[...] um conjunto de práticas que buscam articular as experiências e os saberes das crianças com os conhecimentos que fazem parte do patrimônio cultural, artístico, científico e tecnológico" (BRASIL, 2010, p. 3). O desafio, então, é garantir lugar às experiências sociais dos bebês e crianças em projetos que listam conteúdos a serem trabalhados antes mesmo que 
as crianças entrem na escola. É garantir a participação das crianças na construção dos currículos que, de fato, se proponham a ampliar experiências a partir da escuta e observação atentas.

Paulo Freire (2012) ao afirmar que a nossa terra, o mundo da gente, é o que a gente faz nele, coloca as experiências como produção de saberes sobre o mundo, incluindo o patrimônio artístico, científico, cultural e tecnológico. Suas descrições desses fazeres no mundo são prenhes de ações nas geografias de Santiago do Chile. Elas testemunham a ação de transformar a neve em boneco e o inverno frio em oportunidade para brincar, para pensar sobre a calefação e sua função social. Os conteúdos do mundo físico e sensorial são transformados, nos diálogos, em objetos da curiosidade e do conhecimento. Nesse sentido, a casa e o quintal, casa e jardim, no entanto, não são os lugares de criança. Há uma extensão para o universo metaforizada na atitude de Freire de enviar junto a uma das cartas a Nathercinha, uma fotografia da chegada do homem à lua.

\begin{abstract}
O frio às vezes é maior que Santiago, mas temos boa calefação e abrigos apropriados. (...) E você? E seus estudos? Espero que vovó Nathercia [dê um grande beijo nela por mim], papai, mamãe, seus tios, seus irmãos e primos estejam todos bem. [...] Mando duas fotografias dos primeiros homens na lua (FREIRE in LACERDA, 2016, p. 68-69).
\end{abstract}

Esse trecho é da última carta enviada já de Cambridge, em Massachusetts, nos Estados Unidos, em outubro de 1969. Em papel timbrado da Universidade de Harvard, Paulo Freire adota o mesmo estilo de apresentar o lugar e depois falar da família e das coisas comuns aos dois. Nessas cartas, a dialética criança-mundo e a horizontalidade da relação criança-adulto nos diálogos freirianos com uma criança e sobre a infância atualiza princípios dos círculos de cultura para pensarmos na noção defendida por Freire de espaços dialógicos onde se aprende e se ensina; onde a produção de conhecimentos não acontece por transferência dos adultos às crianças e, principalmente, onde se constroem outras leituras do mundo (FREIRE, 1994). De práticas dialógicas da liberdade e da participação pela via da problematização da vida cotidiana (FREIRE, 1983; FREIRE; BETO, 1985).

Nas cartas, o compartilhamento da alegria e do espanto com as coisas de perto e de longe contracena com a introdução aos problemas cotidianos: as diferenças da língua e dos costumes no Brasil e Chile; a preocupação com o contexto político no Brasil; os impactos ambientais e sociais provocados pela seca; os livros que estava escrevendo e os desafios da inserção em um país com o clima tão diferente; a importância de estudar e a terceira mudança de país; as conquistas da ciência espacial. A problematização da vida cotidiana e a comunicação constante do interesse nas questões levantadas e contadas por Nathercinha, expressa preocupação com a construção do diálogo como um fím em si mesmo, cuja relevância está no ato de dialogar.

\title{
5 Pesquisar e conhecer o mundo: a prática pedagógica como um dado dando-se contra a hegemonia dos pacotes
}

Nos diálogos com Sérgio Guimarães, Paulo Freire argumenta que a tarefa pedagógica teórica das professoras e professores que trabalham com crianças é combater toda forma de discriminação às classes populares e toda forma de autoritarismo, assegurando o "direito de as massas populares dizerem por quê" (FREIRE, 2011, p. 69). No diálogo com as crianças, professoras e professores devem, segundo o educador, se perguntar: "quais os problemas fundamentais que eu encontro com as crianças com as quais eu trabalho? Encontro tais e tais obstáculos? Como eu venho respondendo a eles?” (Ibid. 2011, p. 68).

A tarefa pedagógica definida por Freire contrapõe-se à responsabilização das precárias condições às quais as crianças vivem como justificativa para as pobrezas das práticas, como fica evidente no trecho do diálogo com Sérgio Guimarães. 


\begin{abstract}
É, eu acho que o problema não é tanto porque sejam pedrinhas e tampinhas de garrafa. Acho que isso poderia dar uma excelente educação, se a escola realmente fosse capaz, como espaço político-pedagógico, de aproveitar os recursos naturais, aqueles fragmentos de mundo que as crianças brincam, por exemplo. Seria partir exatamente da brincadeira delas com esses pedaços de coisas e com essas coisas que elas poderiam compreender a razão de ser das próprias coisas (FREIRE; GUIMARÃES, 2011, p. 67).
\end{abstract}

Impossível não notar a semelhança que existe com as proposições curriculares da Educação Infantil (BRASIL, 2010; 2017), quando estas centralizam as interações e brincadeiras como eixos que movem o currículo, como experiências de aprendizagem e desenvolvimento que explicitam modos de participação, interesses, curiosidades, necessidades, intenções e curiosidades das crianças; experiências que podem ser ampliadas pela proposta pedagógica. Partir da brincadeira como modo de comunhão com as coisas e forma de descobrir suas razões de ser. Em síntese, como modo originário de conhecer, algo que vimos em diversos diálogos de Paulo Freire sobre a infância.

Partir da infância e da brincadeira das crianças, no entanto, exige uma atitude dialógica e democrática em relação a elas. Ou como prefere Freire (2011), exige uma tarefa pedagógica teórica de investigar e refletir sobre as questões que as movem e interessam, registrá-las e propor formas de ampliação e problematização da realidade. O que isso diz para as pedagogias da infância? Que o currículo da Educação Infantil não pode ser considerado um dado imutável. Ao invés disso, o currículo em uma pedagogia da infância é sempre um "dado dando-se" (FREIRE, 2011, p. 98), no sentido de que emerge das interações cotidianas.

Ao olhar do que as crianças brincam e como brincam, por exemplo, é possível observar que os acontecimentos sociais as afetam. É possível apreender seus interesses, curiosidades e objetos de conhecimento, assim como suas formas de perceber e imaginar o mundo (SILVA, 2021). É possível, ainda, documentar atitudes, ações, práticas de cuidado de si e dos outros, sentimentos, intenções, ideias, curiosidades e modos de perceber o mundo físico, ambiental, sensorial e simbólico. Portanto, o que fazer e como fazer na relação com as crianças é valorativo do ponto de vista educacional e não pode ser suprimido em nome de uma lista de conteúdos. Essas intenções, curiosidades, desejos, percepções e ideias merecem lugar em um trabalho pedagógico que se proponha, de fato, a acolher e ampliar suas experiências por meio do entrelaçamento com os saberes do patrimônio cultural, artístico, científico e tecnológico.

$\mathrm{O}$ que fazer com isto em uma estrutura institucional que dita o currículo pelo calendário de datas comemorativas ou pela lista programada nos módulos e livros didáticos? Que ciclo de conhecimento acontece em uma prática pedagógica aberta ao cotidiano e às experiências de bebês e crianças? Compartilhar a alegria e espantar-se com as crianças implica: construir uma relação dialógica, discursiva e democrática de quem se deixa afetar por sua curiosidade de saber; ampliar essa curiosidade de saber em diálogo com o imaginário coletivo, os saberes e narrativas que a humanidade já produziu por diferentes meios semióticos; construir espaços/tempos de produção simbólica capazes de colocar os saberes cotidianos em linguagens com as crianças. Tudo isto constitui um ciclo de conhecimento nas pedagogias da infância fundamentadas na ontologia do ser social como ser da transformação.

Partir da infância e começar pelas crianças significa compreendê-las como seres que transformam as práticas com suas perguntas, linguagens movimentos e formas de expressão. Essa concepção de criança como ser social não é mera nomenclatura de projeto político pedagógico. É uma opção política que se torna visível e documentada nas formas de os adultos organizarem espaços e práticas com elas, escutando-as, observando e registrando seus percursos, instigando processos de descoberta pelas experiências cotidianas. $O$ foco nos comportamentos, habilidades e conhecimentos como aprendizagens essenciais que contracena com as experiências das crianças na política nacional de currículo (BRASIL, 2017), nos leva a 
questionar se haveria lugar aberto ao sensível e imaginado, à criação e liberdade, ao espanto e curiosidade para a descoberta, enfim, à produção de sentidos estéticos, políticos e éticos com as crianças em um contexto de alegrias contra a barbárie humana.

\section{Para finalizar, uma canção de luta contra o abandono em tempos de barbárie}

É também à sombra de uma árvore, recuperada em sua escrita no exílio em 1971, que Paulo Freire escreve sua canção óbvia - a da espera esperançosa de quem luta pela educação como prática da liberdade. A luta pelos direitos dos bebês e das crianças à vida, proteção e educação em um contexto de abandono que vivemos desde março de 2020, com o fechamento das escolas e a falta de perspectivas de retorno no centro da organização política nacional, interroga as bases sob as quais e para as quais lutamos.

Quando a educação e os cuidados de um grupo historicamente invisibilizado, como o de bebês e crianças, é a última preocupação em um contexto de crise humanitária como o que vivemos, é porque já falhamos como humanidade. Por outro lado, as disputas no campo dos direitos das crianças como justiça social ante às desigualdades, o abandono e todas as formas de violência, terminam por evidenciar a centralidade da escola como o braço do estado na vida das famílias de classes trabalhadoras e seus filhos e filhas. É essa centralidade que reposiciona nossa luta política pelos projetos de educação e cuidados construídos para estas e com estas crianças.

Em um tempo de pandemia (e após), será preciso investir tempo como experiência que transforma a vida dos bebês e das crianças. Não nos será permitido, sob o risco de incorrer em uma sub-humanidade, invocar ideais de eficiência e eficácia na aplicação dos recursos de educação que sejam medidos por avaliação de desempenho em habilidades pré-definidas.

O limiar entre uma abordagem cognitiva que orienta uma lista de objetivos de aprendizagem e uma abordagem das experiências sociais no interior dos currículos parece insignificante quando se propõe recolocar a escola da infância como projeto de humanização que começa com as crianças; como projeto de vivenciar o tempo da infância como tempo de alegria e descoberta. Desse modo, a obra de Paulo Freire no Brasil pode constituir a base humanista, progressista, democrática, popular de educação, infâncias, docência e direitos humanos.

Um recuo ontológico à infância se desdobra na atenção à temporalidade e complexidade das ações dos bebês e das crianças que constituem sua humanidade e intersubjetividade. Insistimos no valor de evidenciar essas minúcias das linguagens, brincadeiras, perguntas e curiosidades, para defender a dimensão política da participação social dos bebês e crianças. É essa participação que gera motivos, interesses, necessidades, condições para agir no mundo, como diria Paulo Freire (1967). De criar relações pessoais, impessoais, incorpóreas e corpóreas dos quintais ao resto do mundo que "apresentam uma ordem tal de características que as distinguem de puros contatos" (Ibid. p. 39).

A defesa da Educação Infantil como direito é sempre uma escolha política. Com essa escolha afirmamos a defesa de pedagogias da infância participativas, expressivas e, por isso, transformadoras. Nossa canção não nos parece tão óbvia em tempos de ataques à liberdade, de precarização das condições de funcionamento das instituições de Educação Infantil inadequadas para protocolos de distanciamento social e contatos com a natureza. Em tempos em que até mesmo o direito à exploração dos quintais é negado, quer seja pelo confinamento de algumas crianças às telas, quer seja pela expropriação da moradia para muitas. Tempos de desconstrução e ataques à formação estética como um "não tempo" de aprender e de busca desenfreada por resultados de desempenho que, cada vez mais, acentua a distinção entre os projetos de educação público e privado. 
Enquanto esperamos por tempos de quintais e tempos de escola em comunhão com as coisas para todas as crianças, nossa canção é pela mobilização e interlocução entre diferentes atores sociais e entidades de luta pelos direitos das crianças na construção de um pacto humanitário. Um pacto pela vida sim, mas, sobretudo, um pacto pela valorização do tempo de alegria e descoberta desde a Educação Infantil, como princípios de humanização das crianças e transformação de seu entorno social; um pacto pela recuperação das bases políticas que ancoram nossa luta pela educação e cuidados das crianças de nosso país.

\section{Referências}

ANGELO, Adilson de. A pedagogia de Paulo Freire nos quatro cantos da educação da infância. In: CONGRESSO INTERNACIONAL DE PEDAGOGIA SOCIAL. 2006. Mar. 2006. Disponível em:

http://www.proceedings.scielo.br/scielo.php?pid $=\operatorname{msc0000000092006000100001\& script~}=$ sci arttext. Acesso em: 13 jan. 2021.

ARENDT, Hannah. Entre o passado e o futuro. Tradução: Mauro W. Barbosa. 8a. Ed. São Paulo: Perspectiva, 2016.

ARENDT, Hannah. A condição humana. 10. ed. Tradução: Roberto Raposo. Rio de Janeiro: Forense Universitária, 2009.

BARBOSA, Maria Carmem Silveira. A BNCC e os direitos das crianças: Educação Infantil em evidência - Entrevista. Revista Com Censo, ano 13, v. 5, n. 2, maio de 2018. Disponível em: http://www.periodicos.se.df.gov.br/index.php/comcenso/article/view/452. Acesso em: 02 mar. 2021.

BOFF, Leonardo. Saber cuidar: ética do humano - compaixão pela terra. 20 ed. Petrópolis, RJ: Vozes, 2014.

BRASIL. Conselho Nacional de Educação. Câmara de Educação Básica. Resolução n. 05, de 17 de dezembro de 2009. Fixa as Diretrizes Curriculares Nacionais para a Educação Infantil. Brasília, 2010.

BRASIL. Ministério da Educação. Base Nacional Comum Curricular. Brasília: MEC, 2017. BRASIL. Ministério da Educação. Edital PNLD/MEC 2022 de 28/09/2020. Brasília: MEC, 2020.

FREIRE, Paulo. À sombra desta mangueira. 10 ed. Rio de Janeiro: civilização brasileira, 2012.

FREIRE, Paulo. Educação como prática da liberdade. 14. ed. Rio de Janeiro: Paz e Terra, 1983.

FREIRE, Paulo. Pedagogia da Esperança. Um reencontro com a Pedagogia do oprimido. 3. ed. Rio de Janeiro: Paz e Terra, 1994.

FREIRE, Paulo. Pedagogia da autonomia: saberes necessários à prática educativa. São Paulo: Paz e Terra, 1996/97. 
FREIRE, Paulo. Cartas a Cristina: reflexões sobre minha vida e minha práxis. São Paulo: Paz e Terra, 1994.

FREIRE, Paulo. BETTO, Frei. Essa escola chamada vida: depoimentos ao repórter Ricardo Kotscho. São Paulo: Ática, 1985.

FREIRE, Paulo. GUIMARÃES, Sérgio. Partir da infância. Diálogos sobre educação. São Paulo: Paz e Terra, 2011.

HOOKS, Bell. Tudo sobre o amor e outras perspectivas. Tradução: Stephanie Borges. São Paulo: Elefante, 2020.

KOHAN, Walter. Paulo Freire mais do que nunca: uma biografia filosófica. Belo Horizonte: Vestígio, 2019.

KORCZAK, Janusz. Quando eu voltar a ser criança. Tradução: Yan Michalski. São Paulo: Summus, 1981.

LACERDA, Nathercia. A casa e o mundo lá fora: cartas de Paulo Freire para Nathercinha. Rio de Janeiro: ZIT, 2016.

MBEMBE, Achille. Necropolítica: biopoder, soberania, estado de exceção, política da morte. Arte e Ensaios, n. 32, dez. 2016. Disponível em:

https://revistas.unilasalle.edu.br/index.php/redes/article/view/5048. Acesso em: 10 fev. 2021.

NAUDEAU, Sophie et al. Como investir na Primeira Infância: um guia para a discussão de políticas e a preparação de Projetos de Desenvolvimento da Primeira Infância. São Paulo: Singular, 2011.

NAVARRO, Flavia. Calidad del cuidado y la educación para la primera infância en América Latina: Igualdad para hoy y mañana. CEPAL: Santiago de Chile: Nações Unidas, 2014.

ROCHA, Eloísa Acíres Candal; LESSA, Juliana Schumacker; BUSS-SIMÃO, Márcia. Pedagogia da infância: interlocuções disciplinares na pesquisa em educação. Da Investigação às Práticas, Lisboa, v. 6, n. 1, p. 31-49, 2016. Disponível em: https://repositorio.ipl.pt/bitstream/10400.21/6435/1/97-304-1-PB-1.pdf. Acesso em: 20 jan. 2021.

SILVA, Elenice de Brito Teixeira. Do sentido filosófico à significação pedagógica do cuidado. Revista Contemporânea de Educação. v. 12, n. 25, p. 469-485, ago/2017. Disponível em: https://revistas.ufrj.br/index.php/rce/article/view/3665. Acesso em: 15 mar. 2021.

SILVA, Elenice de Brito Teixeira. Atos de criação: as origens culturais da brincadeira dos bebês. Tese de Doutorado. Belo Horizonte, MG: Universidade Federal de Minas Gerais, 2021. 
SILVA, Adelson Ferreira. A questão da curiosidade em Paulo Freire e suas implicações para a formação da criança. In: SANTOS, A. R.; NUNES, C. P. Educação e contextos diversos: implicações políticas e pedagógicas. Jundiaí, SP: Paco Editorial, 2017.

SILVA, Elenice de Brito Teixeira. SILVA, Adelson Ferreira. Cartas de Paulo Freire a uma criança e os princípios de uma pedagogia da infância. Revista Educação em Debate, v. 40, n. 76, 2018. Disponível em:

http://www.periodicosfaced.ufc.br/index.php/educacaoemdebate/article/view/676. Acesso em: 10 mar. 2021.

WILKOMIRSKI, Binjamin. Fragmentos: memórias de uma infância (1939 - 1948).

Tradução: Sérgio Tellaroli. São Paulo: Companhia das Letras, 1988. 